\title{
DIVERSITY OF PHYSICAL AND COOKING QUALITY CHARACTERS OF SELECTED TRADITIONAL AND IMPROVED RICE VARIETIES IN SRI LANKA
}

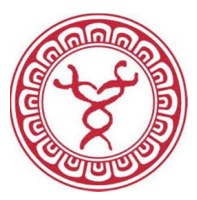

Hettiarachchi, H.A.P.W. ${ }^{1}$, Rebeira , S.P. ${ }^{1,2}$, Prasantha, B.D.R. ${ }^{3 *}$ and Wickramasinghe, H.A.M. ${ }^{4}$

${ }^{1}$ Postgraduate Institute of Agriculture, University of Peradeniya, Peradeniya, Sri Lanka

${ }^{2}$ Rice Research and Development Institute, Department of Agriculture, Bathalagoda, Sri Lanka

${ }^{3}$ Department of Food Science and Technology, Faculty of Agriculture, University of Peradeniya, Peradeniya, Sri Lanka

${ }^{4}$ Department of Agriculture Biology, Faculty of Agriculture, University of Peradeniya, Peradeniya, Sri Lanka

\section{Abstract}

Several physical and cooking quality parameters of fifteen traditional and nine hybrid rice varieties were analyzed. All the tested parameters showed significance variations $(\mathrm{p}<0.05)$ irrespective of being traditional or hybrid varieties. The highest equivalent diameter was observed in Devaraddiri while lowest was recorded for Sudurusamba. The mean kernel volume values ranged from $4.08 \pm 0.01-20.54 \pm 0.13 \mathrm{~mm}^{3}$. The highest kernel length of $6.82 \mathrm{~mm}$ was observed in At 305 and the lowest value of $3.6 \mathrm{~mm}$ was observed in Suwandel. The highest surface area was reported in Devarradiri $\left(5.54 \pm 1.07 \mathrm{~mm}^{2}\right)$ while the lowest value $\left(2.35 \pm 0.27 \mathrm{~mm}^{2}\right)$ was reported in $A t 306 . B w 272-6 B, B g 358, B g$ 360, Suwandel and Sudurusamba recorded high surface area to volume ratios than others varieties. Bulk density varied from $833.9 \pm 1.37 \mathrm{~kg} / \mathrm{m}^{3}$ to $754.2 \pm 0.918 \mathrm{~kg} / \mathrm{m}^{3}$. Bold shape grains of $\mathrm{Bg} 352, \mathrm{Bg} 358$, Suwandel and $B w 267-3$ had the higher bulk density than slender grains of Dikwee, Iginimitiya, Bg 94-1, At 306 and At 405. Porosity was lower in bold shape grains than in slender grains. Minimum and highest cooking time of $15.00 \pm 0.01 \mathrm{~min}$ and 31.00 $\pm 0.24 \mathrm{~min}$ were recorded for At 405 and Herathbanda respectively. Slender rice varieties of Dikwee, Iginimitiya, Bg 94-1, At 306 and At 405, showed a lower solid loss than other grains due to their comparatively low surface area.

Key words: rice, cooking parameters, solid loss, physical properties, surface area 


\section{Introduction}

Rice (Oryza sativa L.) is the staple food crop in world which accounts for $21 \%$, $14 \%$ and $21 \%$ of the global energy, protein and fat supply, respectively (Kennedy and Burlingame, 2003). It is widely cultivated throughout the world and has become the second most important cereal in the world after wheat in terms of cultivation (Jones, 1995). Rice occupied 989,950 ha of the total cultivated area in Sri Lanka, of which 305,314 ha were cultivated in Yala season and 684,636 ha in Maha season (Abesekara et al., 2008). About 0.88 million farmer families are engaged in paddy cultivation and in they produced 3.9 million MT (Yala season; 1,128,984 MT and Maha season; 2,716,961 MT) of paddy annually which fulfills the total domestic requirement (Hafeel et al., 2011). The per capita consumption of rice fluctuates around $114 \mathrm{~kg}$ per year depending on the price of rice, bread and wheat flour (Prasantha et al., 2014). At present cultivation of traditional rice varieties has become more popular due to consumer preference due to their high nutrient value and other functional properties of the rice grain. More than 400 different traditional ice varieties are growing in the country. These varieties are highly diversified among each other with respect to unique nutrient, cooking and eating characteristics (Abesekara et al., 2008).

Rice grain quality is mainly defined by their physical, milling, cooking and eating qualities as well as nutritional quality. Physical and engineering properties of rice grain are important in handling, planting, harvesting, threshing, cleaning, sorting and drying (Irtawange, 2000) and also storage and grain machineries. Principal axial dimensions of rough rice are useful in selecting sieve separators and in calculating power consumption during the rice milling process. Furthermore physical properties of rice grain can also be used to calculate the surface area and volume of kernels which are important for modeling of drying, aeration, heating and cooling of paddy.

Among many quality parameters of rice, cooking and eating qualities are the most important. Consumer preference mainly depends on its cooking and processing quality, which can be measured in terms of water uptake ratio, grain elongation during cooking, solid loss during cooking and cooking time (Bhattacharya and Snowbhagya, 1971). During cooking, water uptake and swelling of the rice granules occur due to water diffusive process (Oko et al., 2012). When water is at sufficiently high temperature $\left(\sim 95{ }^{\circ} \mathrm{C}\right)$, the starch undergoes a gelatinization process (Juliano, 1971). The gelatinization temperature, gel consistency and amylose content directly related to cooking and eating qualities (Little et al., 1958), which are mainly governed by the genotype as well as the environment. The environmental conditions that affect the cooking and eating qualities of rice changes in the day temperature, day length and genotypeenvironment interaction (Jianrong et al., 2005).

Only few studies have been carried out on the physical and cooking quality characteristics of traditional rice varieties in Sri Lanka (Abesekara et al., 2008; Wickramasinghe and Noda, 2008). Nevertheless, local germplasm has not yet been fully evaluated for their physical, engineering and cooking qualities. 
Differences in grain properties can result in a significant variation in the processing characteristics of the grain. Proposed study was carried out to evaluate the diversity of the physical and cooking qualities of rice grain of selected traditional and elite varieties important information for future rice breeding programs and designing of handling, processing, and packaging machinery for rice production.

\section{Material and Methods}

\subsection{Rice grains}

Fifteen traditional and nine hybrid rice varieties (Table 1) were grown at the Rice Research and Development Institute, Bathalagoda in Yala season 2013/2014 under similar management practices. Seeds were collected at the harvest maturity and shade dried up to $12-14 \%$ (dry basis) of moisture content. Seed samples of $150 \mathrm{~g}$ were dehulled (Satake THU 358, Japan) and polished to a level of $8 \pm 2 \%$ of bran removal (Satake THO 50 , Japan) from the total weight.

\subsection{Physical properties of rice}

Length (L), thickness (T) and width (W) of the milled rice kernels were measured using a micrometer. The measurements were taken from randomly selected 10 gains from each variety in triplicate. Size and shape was classified according to the method described by Cruz and Kush (2000). The equivalent diameter $\left(D_{p}\right)$ considering a prolate spheroid shape for a rough rice grain was calculated using equation 1 (Mohsenin, 1986).

$$
D_{\theta}=\left(L \frac{(W+T)^{2}}{4}\right)^{1 / 3}
$$

\section{Whereas;}

$\mathrm{L}=$ Grain length $(\mathrm{mm})$

$\mathrm{T}=$ Thickness $(\mathrm{mm})$

$\mathrm{W}=$ width $(\mathrm{mm})$

Grain volume (V) and surface area (S) of brown rice were calculated using equations 2 and 3 (Varnamkhasti et al., 2008).

$V=0.25\left[\left(\frac{\pi}{6}\right) L(W+T)^{2}\right]$

$S=\frac{\pi B L}{(2 L-B)}$

Sphericity $(\varnothing)$ which is the ratio of surface area of a sphere having the same volume as grain to the surface area was determined using in equation 4 (Mohsenin, 1986).

$\varnothing=\frac{(L W T)^{\frac{1}{3}}}{L} \times 100$

In order to determine kernel weights 100 grains sample selected randomly from each cultivar and the samples were weighed separately (Vidal et al., 2007). The average 100 kernel weight was obtained from five replicates. Sample of weighed rice grains were filled into a graduated measuring cylinder and the volume occupied were recorded to determine the bulk density $(\mathrm{g} / \mathrm{ml})$. True grain density was also measured using kerosene displaced method (Singh et al., 2005). Porosity (\%) was calculated using the equation 5 (Mir et al., 2013). 


\section{Results}

\subsection{Cooking properties of rice}

\subsection{Physical properties of rice}

Cooking properties of the rice samples were determined using standard procedures (Batcher et al., 1956; Singh et al., 2003 and 2005). About of $2 \mathrm{~g}$ of rice sample was cooked in $20 \mathrm{ml}$ of distilled water using a boiling water bath. The minimum time required to cook was estimated by removing few cooked kernels at regular intervals. Few kernels were pressed between two glass slides until no white core was noticed. The time taken to disappear the white core was considered as the minimum time of cooking. The gruel that obtained during the cooking was transferred into a $50 \mathrm{ml}$ beaker and was evaporated in an oven at $110{ }^{\circ} \mathrm{C}$. The solid obtained after drying were weighed and the percentage of the gruel solid loss was calculated. The rest of the cooked samples was weighed $( \pm 0.1$ $\mathrm{mg}$ ) and the water uptake ratio which was the ratio for final cooked weight to uncooked rice weight was calculated (Singh et al., 2003 and 2005). Length of 10 randomly selected cooked rice kernels were measured and was divided by the length of uncooked rice to determine the grain elongation percentage.

\subsection{Data analysis}

Data obtained were subjected to one-way analysis of variance (ANOVA) followed by Duncan's New Multiple Range Test (DNMRT) to determine the statistical differences among varieties at a significance level of $p \leq 0.05$. Statistical analysis was done using SAS software package version 6.1 (SAS, 1990).

Grain physical dimensions among the selected rice varieties (Table 1) varied with respect to the grain size and shape classes. The highest kernel length of 6.82 mm was observed in At 305 and the lowest length of $3.6 \mathrm{~mm}$ was observed in Suwandel. Kernel length of many varieties varied from $5 \mathrm{~mm}$ to $6 \mathrm{~mm}$ while kernel width varied from 2.00 to $2.50 \mathrm{~mm}$. Based on the L of kernels, all selected traditional rice varieties were fallen either into short ( $\leq 5.50 \mathrm{~mm}$ ) or medium (5.51-6.60 mm) grain size classes (Dela Cruz and Khush, 2000). But, there was no any medium size ( $L=5.51-6.6$ ) rice variety was found in the tested hybrid rice varieties. Varieties $A t$ 306, At 405, Bg 94-1, Dikwee and Inginimitiya showed a $\mathrm{L}: \mathrm{W}$ ratio $>3$ indicating that these grains are slender in grain shape. According to the grain size class, Dikwee and Inginimitiya varieties could be categorized into "medium" grain size where At 306, At 405 and $B g$ 94-1 were categorized as "long" grain size class. Therefore long-slender grains of $A t$ 306, At 405 and $B g$ 94-1 can be identified as basmati type rice. Out of 24 rice varieties, there were 5 bold, 5 slender and 14 medium grain shapes were observed. Most of the tested traditional rice varieties belong to medium grain shape category except Suwandel, Dikwee and Inginimitiya (Table 1). Significant differences $(p<0.05)$ were observed in the equivalent diameter among the tested rice varieties (Table 2). The highest equivalent diameter of $3.36 \pm 0.17 \mathrm{~mm}$ was observed in Devaraddiri while lowest value of $1.98 \pm 0.01 \mathrm{~mm}$ was in Sudurusamba. 
Table 1. Physical properties (mean \pm SD) of some selected rice varieties in Sri Lanka

\begin{tabular}{|c|c|c|c|c|c|c|c|}
\hline Rice variety & $\begin{array}{l}\text { Length } \\
\text { (L mm) }\end{array}$ & $\begin{array}{c}\text { Grain } \\
\text { size } \\
\text { class }\end{array}$ & $\begin{array}{l}\text { Width } \\
\text { (W mm) }\end{array}$ & $\begin{array}{l}\text { L/W } \\
\text { ratio }\end{array}$ & $\begin{array}{l}\text { Grain } \\
\text { shape }\end{array}$ & Colour & $\begin{array}{l}100 \text { grain } \\
\text { weight (g) }\end{array}$ \\
\hline \multicolumn{8}{|c|}{ Traditional varieties } \\
\hline Suwandel & $3.69 \pm 0.04$ & Short & $1.80 \pm 0.02$ & 2.05 & Bold & White & $1.03 \pm 0.01$ \\
\hline Dikwee & $5.51 \pm 0.02$ & Medium & $1.74 \pm 0.01$ & 3.17 & Slender & Red & $1.58 \pm 0.03$ \\
\hline Mawee & $5.64 \pm 0.06$ & Medium & $2.14 \pm 0.02$ & 2.64 & Medium & Red & $2.20 \pm 0.00$ \\
\hline Suduheeneti & $5.98 \pm 0.01$ & Medium & $2.14 \pm 0.01$ & 2.79 & Medium & Red & $2.21 \pm 0.01$ \\
\hline Pachchaperuml & $5.22 \pm 0.01$ & Short & $2.34 \pm 0.01$ & 2.23 & Medium & Red & $2.19 \pm 0.01$ \\
\hline Herathbanda & $5.47 \pm 0.01$ & Short & $2.27 \pm 0.01$ & 2.41 & Medium & Red & $2.69 \pm 0.03$ \\
\hline Pokkali & $5.60 \pm 0.05$ & Medium & $2.22 \pm 0.01$ & 2.52 & Medium & Red & $2.04 \pm 0.03$ \\
\hline Sulai & $5.31 \pm 0.01$ & Short & $2.29 \pm 0.01$ & 2.32 & Medium & Red & $2.41 \pm 0.01$ \\
\hline Sudurusamba & $3.90 \pm 0.01$ & Short & $1.48 \pm 0.01$ & 2.64 & Medium & White & $0.83 \pm 0.02$ \\
\hline Kaluheeneti & $5.15 \pm 0.05$ & Short & $2.27 \pm 0.02$ & 2.41 & Medium & Red & $1.75 \pm 0.01$ \\
\hline Wannidahanala & $5.41 \pm 0.01$ & Short & $2.29 \pm 0.01$ & 2.36 & Medium & Red & $2.11 \pm 0.01$ \\
\hline Dular & $5.38 \pm 0.05$ & Short & $2.12 \pm 0.02$ & 2.54 & Medium & White & $1.89 \pm 0.01$ \\
\hline Inginimitiya & $5.78 \pm 0.02$ & Medium & $1.7 \pm 0.10$ & 3.40 & Slender & White & $1.48 \pm 0.01$ \\
\hline Kahatawee & $5.63 \pm 0.01$ & Medium & $2.34 \pm 0.01$ & 2.41 & Medium & Red & $2.39 \pm 0.01$ \\
\hline Dewaraddiri & $5.45 \pm 0.02$ & Short & $2.58 \pm 0.14$ & 2.11 & Medium & Red & $2.37 \pm 0.03$ \\
\hline \multicolumn{8}{|l|}{ Hybrid varieties } \\
\hline $\mathrm{Bg} 360$ & $4.04 \pm 0.2$ & Short & $1.70 \pm 0.01$ & 1.74 & Bold & White & $1.08 \pm 0.03$ \\
\hline Bg 352 & $5.30 \pm 0.01$ & Short & $2.31 \pm 0.01$ & 2.28 & Medium & White & $2.20 \pm 0.02$ \\
\hline Bg 94-1 & $6.19 \pm 0.02$ & Long & $1.90 \pm 0.01$ & 3.24 & Slender & White & $2.25 \pm 0.01$ \\
\hline$B g 366$ & $5.30 \pm 0.04$ & Short & $2.21 \pm 0.02$ & 2.39 & Medium & White & $2.02 \pm 0.01$ \\
\hline Bg 358 & $3.88 \pm 0.03$ & Short & $2.01 \pm 0.05$ & 1.93 & Bold & White & $1.33 \pm 0.01$ \\
\hline$B w 267-3$ & $3.97 \pm 0.01$ & Short & $2.06 \pm 0.01$ & 1.92 & Bold & White & $1.68 \pm 0.01$ \\
\hline$B w 272-6 B$ & $3.97 \pm 0.03$ & Short & $2.06 \pm 0.01$ & 1.92 & Bold & White & $1.31 \pm 0.01$ \\
\hline At 306 & $6.82 \pm 0.03$ & Long & $1.63 \pm 0.20$ & 4.18 & Slender & White & $1.99 \pm 0.01$ \\
\hline At 405 & $6.53 \pm 0.05$ & Long & $1.61 \pm 0.01$ & 4.05 & Slender & White & $1.96 \pm 0.01$ \\
\hline
\end{tabular}

The kernel volume and surface area showed significant differences $(p<0.05)$ among the rice cultivars. The mean kernel volume ranged from $4.08 \pm 0.01 \mathrm{~m}^{3}$ in Sudurusamba to $20.54 \pm 0.13 \mathrm{~m}^{3}$ in Dewaraddiri. The highest surface area was reported in Dewaraddiri as $5.54 \pm 1.07$ $\mathrm{mm}^{2}$ and the lowest value was reported in $A t$ 306. Rice varieties $B w$ 272-6B, $B g$ 358, Bg 360, Suwandel and Sudurusamba recorded more than $>50$ surface area to volume ratio (Table 2). Except Sudurusamba other others varieties were categorized as "bold" grain shape (Table 
1). The sphericity values of the tested rice varieties were in the range of 33.764\%. Significant differences $(\mathrm{p}<0.05)$ were also observed among the sphericity values of tested rice varieties (Table 2).

Table 2. Variation of equivalent diameter, surface area, volume and sphericity of the tested rice varieties.

\begin{tabular}{|c|c|c|c|c|c|}
\hline Rice variety & $\begin{array}{c}\text { Equalant } \\
\text { diameter } \\
(\mathrm{mm})\end{array}$ & $\begin{array}{l}\text { Volume } \\
\left(\mathrm{V} \mathrm{mm}^{3}\right)\end{array}$ & $\begin{array}{c}\text { Surface area } \\
\left(\mathrm{SA} \mathrm{mm} \mathrm{mm}^{2}\right)\end{array}$ & $\begin{array}{l}\text { SA:V } \\
\text { ratio }\end{array}$ & Sphericity (\%) \\
\hline \multicolumn{6}{|c|}{ Traditional varieties } \\
\hline Suwandel & $2.24 \pm 0.02^{\mathrm{H}^{*}}$ & $5.92 \pm 0.12^{\mathrm{GHI}}$ & $3.47 \pm 0.06^{\mathrm{F}}$ & 58.61 & $58.71 \pm 0.6 \mathrm{~J}$ \\
\hline Dikwee & $2.35 \pm 0.01^{\mathrm{GH}}$ & $6.88 \pm 0.15^{\mathrm{G}}$ & $2.77 \pm 0.06^{\mathrm{BC}}$ & 40.26 & $42.64 \pm 0.03^{\mathrm{K}}$ \\
\hline Mawee & $2.96 \pm 0.01^{\mathrm{BDC}}$ & $13.59 \pm 0.22^{\mathrm{B}}$ & $3.99 \pm 0.04 J$ & 29.36 & $50.00 \pm 0.03^{\mathrm{H}}$ \\
\hline Suduheeneti & $2.90 \pm 0.01^{\mathrm{B}}$ & $12.91 \pm 0.1^{\mathrm{B}}$ & $3.82 \pm 0.04^{\mathrm{BC}}$ & 29.60 & $48.53 \pm 0.14^{\mathrm{C}}$ \\
\hline Pachchaperumal & $2.95 \pm 0.01^{\mathrm{B}}$ & $13.53 \pm 0.06^{\mathrm{B}}$ & $4.23 \pm 0.03^{\mathrm{DE}}$ & 31.26 & $53.73 \pm 0.01^{\mathrm{FG}}$ \\
\hline Herathbanda & $2.98 \pm 0.01^{\mathrm{BI}}$ & $13.88 \pm 0.2^{\mathrm{B}}$ & $4.35 \pm 0.03^{\mathrm{CD}}$ & 31.34 & $55.01 \pm 0.1^{\mathrm{F}}$ \\
\hline Pokkali & $2.93 \pm 0.01^{\mathrm{B}}$ & $13.23 \pm 0.14^{\mathrm{B}}$ & $4.16 \pm 0.05^{J}$ & 31.44 & $53.08 \pm 0.4^{\mathrm{B}}$ \\
\hline Sulai & $2.90 \pm 0.01^{\mathrm{CD}}$ & $12.83 \pm 0.11^{\mathrm{C}}$ & $4.41 \pm 0.04^{\mathrm{E}}$ & 34.37 & $57.36 \pm 0.2^{\mathrm{G}}$ \\
\hline Sudurusamba & $1.98 \pm 0.01^{\mathrm{J}}$ & $4.08 \pm 0.03^{\mathrm{I}}$ & $2.94 \pm 0.02^{\mathrm{BC}}$ & 72.05 & $55.90 \pm 0.17^{\mathrm{E}}$ \\
\hline Kaluheeneti & $2.79 \pm 0.07 \mathrm{CD}$ & $11.50 \pm 0.8^{\mathrm{C}}$ & $3.85 \pm 0.40^{\mathrm{BC}}$ & 33.48 & $51.24 \pm 1.7^{\mathrm{H}}$ \\
\hline Wannidahanala & $2.92 \pm 0.01 \mathrm{CD}$ & $13.21 \pm 0.1^{\mathrm{CD}}$ & $4.20 \pm 0.03^{\mathrm{IJ}}$ & 31.80 & $53.81 \pm 0.15^{\mathrm{FG}}$ \\
\hline Dular & $2.46 \pm 0.06^{\mathrm{HG}}$ & $7.92 \pm 0.63^{\mathrm{GH}}$ & $2.96 \pm 0.29 \mathrm{HG}$ & 37.37 & $44.30 \pm 0.07^{\mathrm{M}}$ \\
\hline Iginimitiya & $2.37 \pm 0.01^{\mathrm{GH}}$ & $7.00 \pm 0.08 \mathrm{GH}$ & $2.74 \pm 0.03^{\mathrm{BC}}$ & 39.14 & $40.98 \pm 0.12^{\mathrm{L}}$ \\
\hline Kahatawee & $3.04 \pm 0.01^{\mathrm{B}}$ & $14.85 \pm 0.08^{\mathrm{B}}$ & $4.36 \pm 0.02^{\mathrm{B}}$ & 29.36 & $53.66 \pm 0.1^{\mathrm{G}}$ \\
\hline Dewaraddiri & $3.36 \pm 0.17^{\mathrm{A}}$ & $20.54 \pm 4.0^{\mathrm{A}}$ & $5.54 \pm 1.07 \mathrm{E}$ & 26.97 & $62.15 \pm 2.62^{\mathrm{I}}$ \\
\hline \multicolumn{6}{|l|}{ Hybrid varieties } \\
\hline $\mathrm{Bg} 360$ & $2.17 \pm 0.01^{\mathrm{JI}}$ & $5.37 \pm 0.05^{\mathrm{HI}}$ & $3.14 \pm 0.03^{\mathrm{E}}$ & 58.47 & $54.18 \pm 0.24^{C}$ \\
\hline Bg 352 & $2.93 \pm 0.01^{\mathrm{B}}$ & $13.50 \pm 0.1^{\mathrm{B}}$ & $4.37 \pm 0.04^{\mathrm{BC}}$ & 32.37 & $55.73 \pm 0.15^{J}$ \\
\hline$B g$ 94-1 & $2.74 \pm 0.01^{\mathrm{D}}$ & $10.87 \pm 0.12^{\mathrm{ED}}$ & $3.37 \pm 0.36^{\mathrm{B}}$ & 31.00 & $44.35 \pm 0.55^{\mathrm{A}}$ \\
\hline$B g 366$ & $2.87 \pm 0.17^{\mathrm{BDC}}$ & $12.47 \pm 0.22^{\mathrm{B}}$ & $4.11 \pm 0.04^{\mathrm{B}}$ & 33.00 & $53.67 \pm 0.2^{\mathrm{FG}}$ \\
\hline $\mathrm{Bg} 358$ & $2.32 \pm 0.02^{\mathrm{H}}$ & $6.61 \pm 0.2^{\mathrm{GHI}}$ & $3.64 \pm 0.15^{\mathrm{I}}$ & 55.07 & $59.39 \pm 0.8^{\mathrm{E}}$ \\
\hline$B w 267-3$ & $2.68 \pm 0.08^{\mathrm{E}}$ & $10.18 \pm 0.01^{\mathrm{EF}}$ & $3.66 \pm 0.03 \mathrm{~J}$ & 36.00 & $50.67 \pm 0.14 \mathrm{FG}$ \\
\hline$B w 272-6 B$ & $2.52 \pm 0.01^{\mathrm{I}}$ & $8.39 \pm 0.1^{\mathrm{FG}}$ & $4.25 \pm 0.07 \mathrm{IJ}$ & 50.66 & $63.98 \pm 0.55^{\mathrm{N}}$ \\
\hline At 306 & $2.34 \pm 0.01^{\mathrm{H}}$ & $6.86 \pm 0.1^{\mathrm{GHI}}$ & $2.35 \pm 0.27^{\mathrm{H}}$ & 34.26 & $33.71 \pm 0.2^{\mathrm{H}}$ \\
\hline At 405 & $2.51 \pm 0.01^{\mathrm{GF}}$ & $8.28 \pm 0.01^{\mathrm{FG}}$ & $2.73 \pm 0.03^{\text {В }}$ & 33.00 & $37.64 \pm 0.3^{\mathrm{H}}$ \\
\hline
\end{tabular}

* Mean $( \pm$ SD) followed by the same superscript letter in each columns are not significantly different $(p>0.05)$. 
The Figure 1 shows the variation of true density, bulk density and porosity values among the selected rice varieties. Bulk density was ranged from $833.9 \pm 1.37$ $\mathrm{kg} / \mathrm{m}^{3}$ to $754.2 \pm 0.918 \mathrm{~kg} / \mathrm{m}^{3}$. The highest bulk density of $833.9 \pm 1.37 \mathrm{~kg} / \mathrm{m}^{3}$ was observed in the variety $\mathrm{Bg} 360$ and followed by the other bold shape rice varieties of Suwandel, $B g$ 358, Bw 267-3 and $B w$ 272-6B. However, slender varieties such as Dikwee, Iginimitiya, At 405, At 306 and $B g$ 94-1 had the low bulk density values. Variety $A t 405$ had the lowest bulk density value of $754.2 \pm 0.918$ $\mathrm{kg} / \mathrm{m}^{3}$.

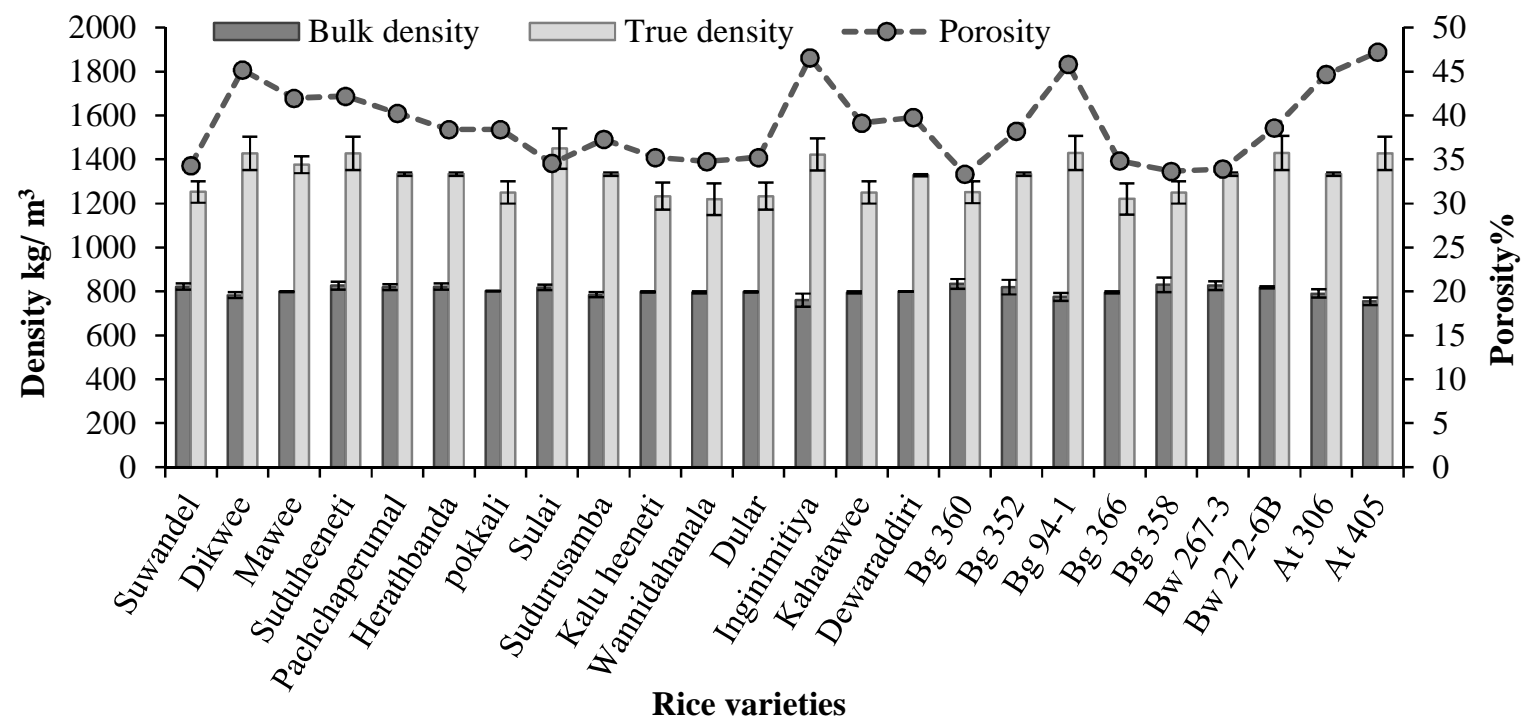

Figure 1. Variation of true density, bulk density and porosity among tested traditional and improved rice varieties. Vertical lines indicate the mean \pm SD.

According to the grain dimensions, all traditional rice varieties fitted to the grain shape of medium or bold category except Dikwee and Inginimitiya which had the mean bulk density value of $801.44 \pm 8.72$ $\mathrm{kg} / \mathrm{m}^{3}$. True density showed least variation among the varieties, ranging from $1220.00 \pm 36.45 \mathrm{~kg} / \mathrm{m}^{3}$ to $1428.57 \pm 38.78 \mathrm{~kg} / \mathrm{m}^{3}$ with an average of $1321 \pm 39.01 \mathrm{~kg} / \mathrm{m}^{3}$. Grain porosity values ranged from $33.67 \pm 1.88 \%$ to $47.2 \pm 3.0 \%$. The highest value for porosity was recorded for At 405 followed by Inginimitiya, Dikwee, Bg 94-1 and At 306.
In contrast to bulk density, higher porosity values were observed for slender rice varieties while lower values were observed for bold shape varieties.

\subsection{Cooking properties of rice}

Table 3 shows the variation of cooking characteristic data among the tested rice varieties. A significant difference $(p<0.05)$ was observed for minimum cooking time among the selected rice varieties. Minimum and highest cooking times of $15.00 \pm 0.01 \mathrm{~min}$ and $31.00 \pm 0.24 \mathrm{~min}$ were recorded for At 405 and Herathbanda respectively. Solid loss was ranged from 
$3.2 \pm 0.5 \%$ in Devaraddiri to $7.7 \pm 0.2 \%$ in $A t$ 306 showed significant differences $(\mathrm{p}<0.05)$ among the tested varieties (Figure 2).

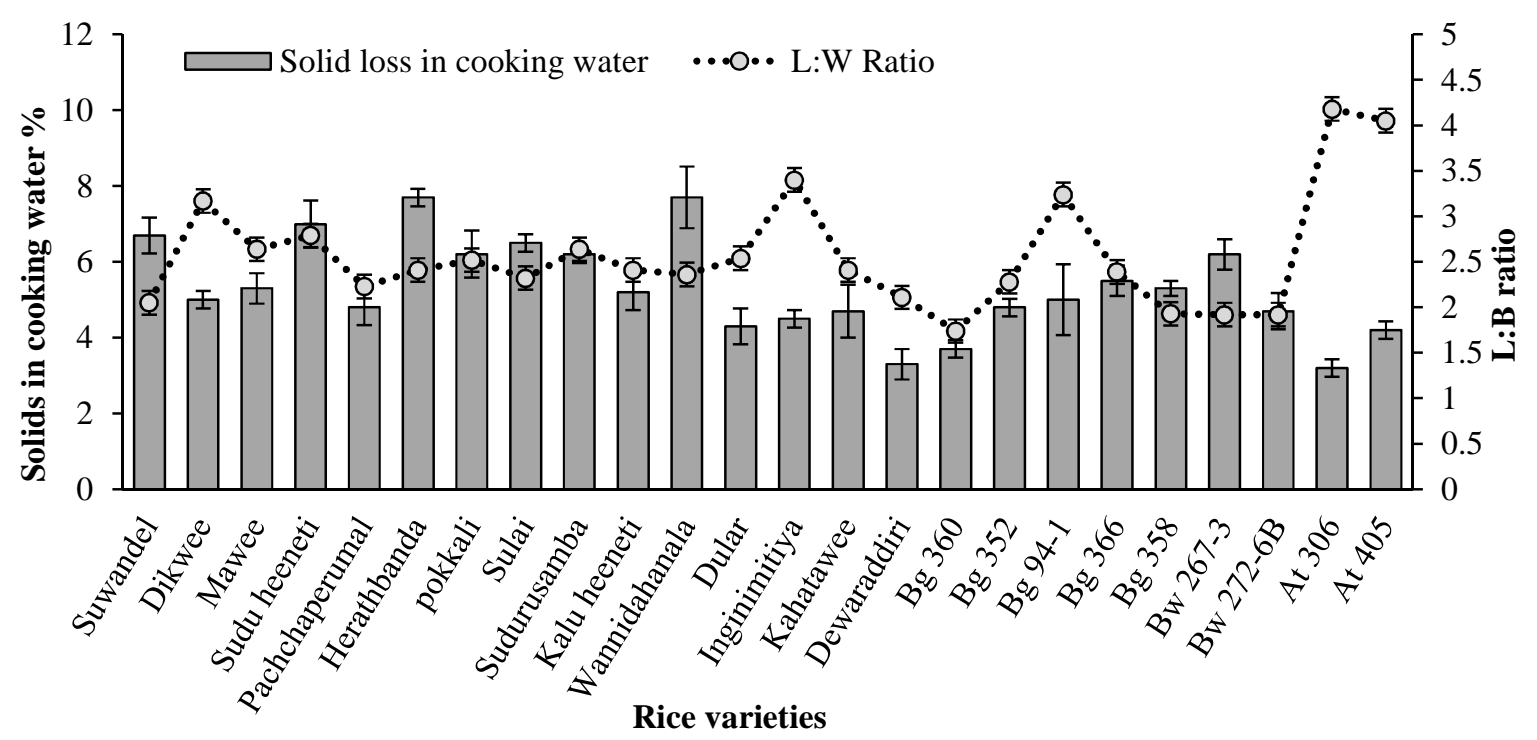

Figure 2. Variation of solid loss in cooking water with L:W ratio among selected rice varieties in Sri Lanka. Vertical lines indicate the mean $\pm S D$.

Water uptake ratio also showed significance differences $(\mathrm{p}<0.05)$ among the selected rice varieties (Table 3 ). Lowest water uptake ratio of $2.13 \pm 0.01$ was reported for Dular while highest water uptake of $3.40 \pm 0.17$ was reported for $B g$ 352. The values for grain elongation during cooking ranged from $14.96 \pm 0.22 \mathrm{~mm}$ to $64.09 \pm 2.42 \mathrm{~mm}$ recorded for Kahatawee and $\mathrm{Bg} 352$ respectively.

\section{Discussion}

\subsection{Physical properties of rice}

Physical appearance of the rice kernels varies according to its size and shape which is highly important for rice marketability. It is important to classify the grains based on their shape to determine the extent of off-size in market grades (Varnamkhasti et al., 2008) which is also important for milling. The size and shape of rice grain is determined by $\mathrm{L}, \mathrm{W}$ and L:W ratio. Long, medium and short grain size classes depend on the kernel $\mathrm{L}$ of 6.61-7.50 mm, 5.51-6.60 mm and $\leq 5.50$ $\mathrm{mm}$, respectively (Cruz and Khush, 2000). Nevertheless, slender, medium and bold grain shape classes are subjected to the $\mathrm{L}: \mathrm{W}$ ratios of $>3,2.1-3$ and $\leq 2$ respectively. Grain physical dimensions results of this study are in compatible with Samal et al. (2014) who reported that grain length and width of the traditional aromatic rice varieties is in the range of $4.90-12.41 \mathrm{~mm}$ and $1.80-3.50$ $\mathrm{mm}$ respectively. Sphericity values of 
traditional and hybrid rice reported in this study was within the range of 33$64 \%$. These values are in accordance with the previous data within the range of 32\%-100\% reported by Mohsenin (1986).

Table 3. Mean $( \pm S D)$ of minimum cooking time, water uptake ratio, solids in cooking water and grain elongation ratio of some selected rice varieties of Sri Lanka

\begin{tabular}{|c|c|c|c|}
\hline Rice variety & Minimum cooking time (min.) & Grain elongation $(\%)$ & Water uptake ratio \\
\hline \multicolumn{4}{|c|}{ Traditional varieties } \\
\hline Suwandel & $21.33 \pm 0.48^{\mathrm{FG}^{*}}$ & $51.18 \pm 1.13^{\mathrm{CD}}$ & $2.44 \pm 0.01^{\mathrm{FG}}$ \\
\hline Dikwee & $24.33 \pm 0.24^{\mathrm{D}}$ & $46.89 \pm 0.63^{\mathrm{D}}$ & $3.17 \pm 0.33^{\mathrm{BDA}}$ \\
\hline Mawee & $21.00 \pm 0.02^{\mathrm{D}}$ & $24.12 \pm 0.27^{\mathrm{HG}}$ & $2.97 \pm 0.04^{\mathrm{DE}}$ \\
\hline Suduheeneti & $26.67 \pm 0.24^{\mathrm{D}}$ & $20.37 \pm 0.76^{\mathrm{HG}}$ & $3.20 \pm 0.02^{\mathrm{BCA}}$ \\
\hline Pachchaperumal & $26.33 \pm 0.24^{\mathrm{B}}$ & $63.01 \pm 0.19^{\mathrm{A}}$ & $2.75 \pm 0.02^{\mathrm{FG}}$ \\
\hline Herathbanda & $31.00 \pm 0.24^{\mathrm{A}}$ & $50.4 \pm 2.25^{\mathrm{CD}}$ & $3.21 \pm 0.03^{\mathrm{HG}}$ \\
\hline pokkali & $21.33 \pm 0.01^{\mathrm{C}}$ & $41.44 \pm 0.41^{\mathrm{E}}$ & $3.20 \pm 0.11^{\mathrm{BA}}$ \\
\hline Sulai & $30.00 \pm 0.01^{\mathrm{B}}$ & $25.91 \pm 0.96^{\mathrm{G}}$ & $2.74 \pm 0.02^{\mathrm{FG}}$ \\
\hline Sudurusamba & $20.00 \pm 0.1^{\mathrm{H}}$ & $63.35 \pm 0.78^{\mathrm{A}}$ & $2.45 \pm 0.02^{\mathrm{FG}}$ \\
\hline Kaluheeneti & $20.00 \pm 0.1^{\mathrm{H}}$ & $51.39 \pm 3.84^{\mathrm{CD}}$ & $2.77 \pm 0.05^{\mathrm{H}}$ \\
\hline Wannidahanala & $28.67 \pm 0.2^{\mathrm{B}}$ & $46.76 \pm 0.78^{\mathrm{D}}$ & $2.58 \pm 0.01^{\mathrm{HG}}$ \\
\hline Dular & $25.67 \pm 0.48^{\mathrm{C}}$ & $22.25 \pm 0.58^{\mathrm{HGI}}$ & $2.13 \pm 0.01^{\mathrm{I}}$ \\
\hline Inginimitiya & $20.00 \pm 0.48^{\mathrm{H}}$ & $19.43 \pm 0.65^{\mathrm{HJI}}$ & $2.82 \pm 0.06^{\mathrm{FE}}$ \\
\hline Kahatawee & $22.33 \pm 0.10^{\mathrm{EF}}$ & $14.96 \pm 0.22^{\mathrm{J}}$ & $2.56 \pm 0.12^{\mathrm{GH}}$ \\
\hline Dewaraddiri & $18.00 \pm 0.24^{\mathrm{I}}$ & $56.73 \pm 0.1^{\mathrm{B}}$ & $2.54 \pm 0.03^{\mathrm{GH}}$ \\
\hline \multicolumn{4}{|l|}{ Hybrid varieties } \\
\hline Bg 360 & $18.00 \pm 0.01^{\mathrm{I}}$ & $22.93 \pm 2.39^{\mathrm{HGI}}$ & $2.46 \pm 0.05^{\mathrm{GH}}$ \\
\hline Bg 352 & $19.00 \pm 0.01^{\mathrm{B}}$ & $64.09 \pm 2.42^{\mathrm{A}}$ & $3.40 \pm 0.17^{\mathrm{A}}$ \\
\hline Bg 94-1 & $30.33 \pm 0.12^{\mathrm{A}}$ & $54.97 \pm 1.15^{\mathrm{CB}}$ & $3.09 \pm 0.02^{\mathrm{CB}}$ \\
\hline Bg 366 & $22.00 \pm 0.60^{\mathrm{GH}}$ & $62.95 \pm 2.48^{\mathrm{A}}$ & $3.39 \pm 0.04^{\mathrm{A}}$ \\
\hline Bg 358 & $21.33 \pm 0.12^{\mathrm{DE}}$ & $17.59 \pm 0.28^{\mathrm{JI}}$ & $3.02 \pm 0.17^{\mathrm{BCA}}$ \\
\hline$B w 267-3$ & $28.50 \pm 0.48^{\mathrm{B}}$ & $31.83 \pm 0.80^{\mathrm{F}}$ & $3.18 \pm 0.17^{\mathrm{BCA}}$ \\
\hline$B w 272-6 B$ & $20.00 \pm 0.01^{\mathrm{H}}$ & $46.76 \pm 3.08^{\mathrm{D}}$ & $3.30 \pm 0.08^{\mathrm{D}}$ \\
\hline At 306 & $18.00 \pm 0.41^{\mathrm{I}}$ & $24.75 \pm 0.08^{\mathrm{HG}}$ & $2.25 \pm 0.04^{\mathrm{GH}}$ \\
\hline At 405 & $15.00 \pm 0.01^{\mathrm{J}}$ & $16.07 \pm 1.61^{\mathrm{J}}$ & $2.26 \pm 0.01^{\mathrm{J}}$ \\
\hline
\end{tabular}

*Mean \pm SD followed by the same superscript letter are not significantly different ( $>>0.05$ ) from each other in each columns 
The value reported for the bulk density in the present study was similar to the findings of Bhattacharya et al. (1972).

Bulk density was independent from the rice length, width and weight but inversely related to $\mathrm{L}: \mathrm{W}$ ratio or with respect to the grain shape. Round grains showed the higher bulk density and slender grains showed the lowest, as described by Correa et al. (2007). The knowledge of bulk density is useful to design grain storage silos and hoppers for grain handling during processing (Nalladulai et al., 2002).

\subsection{Cooking properties of rice}

Minimum cooking time values reported in this study was within the previously reported rang of 13-25 min (Oko et al., 2012). The variation in the cooking time among different varieties could be related to the gelatinization temperature of rice. It has been found that gelatinization temperature is directly proportional to the cooking time of rice (Bhattacharya and Snowbhagya, 1971). However, At 405, At 306, Bg 352, Mawee, and Pokkali that fall into high gelatinized temperature class (Abesekara et al., 2008; Rebeira et al., 2014) showed low cooking time. Traditional rice variety Sulai was categorized as low gelatinization temperature class with higher cooking time. Most of the other varieties were categorized as an intermediate gelatinization temperature class and had the comparatively high cooking time (Abesekara et al., 2008).

Solids loss of rice during cooking is considered as a parameter of cooking quality attribute (Julliano, 1971). Low solid loss contents in the gruel can be attributed to the slender rice varieties having comparatively smaller surface area. These observations were comparable to those reported by Hirannaiah et al. (2001). Rice varieties with higher amylose content are prone to leaching out solids into the cooking water as starch granules during cooking (Juliano, 1971). According to Rebeira et al. (2014), Herathbanda, Wannidahanala, Suduheeneti, Pokkali, Sulai and Bw 267-3 are categorized as high amylose rice and are shown to have higher solid loss into the cooking water. Frei and Becker (2003) reported that rice with high amylose content tends to absorb more water during cooking. According to the results high amylose rice varieties such as $\mathrm{Bg}$ 352, Bg 358, Herathbanda, Pokkali, Dikwee, and Kaluheeneti showed higher water uptake while At 405, At 306, sudurusamba and $B g 360$ which was categorized as low amylose group (Abesekara et al., 2008) showed low water up take ratio. The extent of water absorbed by rice during cooking is considered as an economic quality as it gives some estimate of volume increase during cooking.

Elongation of rice grains during cooking is dependent basically on rice variety and degree of milling (Mohapatra and Bal, 2006). Expansion of size in length-wise without increase in width during cooking is considered as a highly desirable quality characteristic rice grain. Water uptake is directly related to taste and consistency of rice and thus high water uptake indicates good quality (Shittu et al., 2012, Verma et al., 2013). The rice varieties which absorbed high quantity of water during cooking are soft varieties and these varieties which absorb low amount of water during cooking considered as hard rice varieties. 


\section{Conclusion}

This investigation has showed that the physical properties and cooking related characteristics of the different varieties of Sri Lankan rice vary significantly according to the size classes. The wide variation of bulk density, porosity, water uptake ratio and grain elongation were recorded for rice varying from short to long varieties. Regardless of traditional or hybrid improved slender grain rice varieties showed desirable cooking characteristics and better physical properties for milling.

\section{Acknowledgement}

Financial assistance provided by the National Research Council through grant NRC-11-86 is highly acknowledged. Bathalagoda Rice Research Institute is gratefully acknowledged for providing rice samples and technical support respectively.

\section{References}

Abesekara, W.K.S.M., Somasiri, H.P.P.S., Premakumara, G.A.S., Benthota, A.P., Rajapakse, D., Ediriweera, N. (2008). Cooking and eating quality traits of some Sri Lankan traditional rice varieties across Yala and Maha seasons: Tropical Agriculture Research 20, 168-176.

Batcher,O.M., Helmintoller, K. F., Dawson, E.H. (1956). Development and application of method for evaluating cooking and eating quality of rice. Rice Journal 59:4-8, 32.

Bhattacharya, K.R. and Sowbhagya, C.M., Swamy, Y. M.I. (1972). Some physical properties of paddy and rice and their interrelations. Science of Food and Agriculture, 23, 171-186.

Bhattacharya, K.R., Sowbhagya, C.M. (1971). An improved alkali reaction test for rice quality. International Journal Food Science and Technology 7, 323-33.

Correa, P. C., Silva, F. S., Jaren, C., Junior, P. C. A., Arana, I. (2007). Physical and mechanical properties in rice processing. Journal of Food Engineering 79, 137-142.

Cruz, D.N., Khush, G.S. (2000). Rice grain quality evaluation procedures. In: R.K. Singh and U.S. Singh and G.S. Khush (eds.), Aromatic Rice. pp. 1528, Oxford and IBH Publishing Co. Pvt. Ltd., New Delhi and Calcutta.

Frei, M., Becker, K., (2003). Studies on the in-vitro starch digestibility and glycemic index of six different indigenous rice cultivars from the Philippines. Journal of Food Chemistry 83, 395400.

Hafeel, R.F., Prasantha, B.D.R., Dissanayke, D.M.N., Edirisinghe, E.M.R.D. (2011). Hermetic storage method, a promising alternative for rice storage. Annals of the Sri Lanka Department of Agriculture 13, 59-70.

Hirannaiah, B. V., Bhashyam, M. K., Ali, S. Z. (2001). An improved cooking quality test for Basmati rice. Journal of Food Science and Technology 38, 116119.

Irtawange, S.V., (2000). The effect of accession on some physical and engineering properties of African yam bean. Unpublished Ph.D. Thesis, Department of Agricultural Engineering, University of Ibadan, Nigeria.

Jianrong, L., Chunhi, S., Mingguo ,W., Jianguo, W. (2005). Analysis of genetic effect for cooking quality traits of japonica rice across environments. Plant Science 168, 1501-1506.

Jones, M. P. (1995). The rice plant and its environment. WARDA Training Guide, 2, 27 -30 p.

Juliano, B.O. (1971). A simplified assay for milled rice amylose. Cereal Science Today 16, 334-338.

Kennedy. G., Burlingame, B. (2003). Analysis of food composition data on rice from a plant genetic resources perspective. Food Chemistry 80, 589596.

Little, R.R., Hilder, G.B., Dawson, E.H., Elsie, H. (1958). Differential effect of dilute alkali on 25 varieties of milled white rice. Cereal Chemistry 35, 111-121. 
Mir, S, A., Bosco, S. J. D., Sunooj, K. V. (2013). Evaluation of physical properties of rice cultivars grown in the temperate region of India. International Food Research Journal 20, 15211527.

Mohapatra, D., Bal, S. (2006). Cooking quality and instrumental textural attributes of cooked rice for different milling fractions. Journal of Food Engineering 73, 253-259.

Mohsenin, N.N., (1986). Physical Properties of Plant and Animal Materials. Second edition; Gordon and Breach Science Publishers, New York, USA. 742 p.

Nalladulai, K., Alagusundaram, K., Gayathri, P. (2002). Airflow resistance of paddy and its byproducts. Biosystems Engineering 831, 67-75.

Oko, A. O., Ubi B. E., Dambaba N. (2012). Rice cooking quality and physico-chemical characteristics: a comparative analysis of selected local and newly introduced rice varieties in Ebonyi state, Nigeria. Food and Public Health 2, 43- 49 .

Prasantha, B.D.R., Hafeel, R.F., Wimalasiri, K.M.S., Pathirana, U.P.D. (2014). End-use quality characteristics of hermetically stored paddy. Journal of Stored Product Research 59, 158-1.

Rebeira, S. P., Wickramasinghe, H. A. M., Samarasinghe, W. L. G., Prasantha, B. D. R. (2014). Diversity of grain quality characteristics of traditional rice (Oryza sativa L.) varieties in Sri Lanka. Tropical Agriculture Research 20, 168-176.

Samal, K. C., Rout, G. R., Das, S. R. (2014). Study of genetic divergence of Indigenous Aromatic Rice (Oryza sativa L.): Potentials and consequences of on-farm management in traditional farming. International Journal of Agricultural Sciences 4, 176-189.
SAS (1990). SAS language and procedures, version $6.1^{\text {st }}$ edition. SAS Institute, Cary, NC, 638 p.

Shittu, T. A., Olaniyi, M. B., Oyekanmi, A. A., Okeleye, K. A. (2012). Physical and water absorption characteristics of some improved rice varieties. Food and Bioprocess Technology 5, 298309.

Singh, N., Kaur, L., Singh, S.N., Sekhon, K.S. (2005). Physicochemical, cooking and textural properties of milled rice from different Indian rice cultivars. Food Chemistry 89, 253-259.

Singh, N., Sodhi, N. S., Kaur, M., Saxena, S. K. (2003). Physico-chemical, morphological, thermal, cooking and textural properties of chalky and translucent rice kernels. Food Chemistry 82, 433439.

Sompong, R., Siebenhandl-Ehn, S., LinsbergerMartin, G., Berghofer, E. (2012). Physicochemical and antioxidative properties of red and black rice varieties from Thailand, China and Sri Lanka. Food Chemistry 124, 132-140.

Varnamkhasti, M. G., Mobli, H., Jafari, A., Keyhani, A. R., Soltanabadi, M. H., Rafiee, S., Kheiralipour, K. (2008). Some physical properties of rough rice (Oryza sativa L.) grain. Journal of Cereal Science 47, 496-501.

Verma, D. K., Mohan, M., Asthir, B. (2013). Physicochemical and cooking characteristics of some promising basmati genotypes. Asian Journal of Food and Agro-Industry 6, 94-99.

Vidal. Pons, B., Brunnschwerler, J., Handschin, S., Rouau, X., Mestres, C. (2007). Cooking behavior of rice in relation to kernel physicochemical and structural properties. Journal of Agriculture and Food Chemistry 55, 336-346.

Wickramasinghe, H.A.M., Noda, T. (2008). Physicochemical properties of starches from Sri Lankan rice varieties. Food Science and Technology Research 14, 49-54. 